\title{
Kaizen Dissemination Through the Government and Private Sector in Southeast Asia: A Comparative Study of Malaysia, Indonesia, and Myanmar
}

\section{Toru Homma}

\section{INTRODUCTION}

Kaizen is an integral part of Japanese-style management (Imai 1986). Dissemination of Kaizen has accelerated in East Asia as Japanese companies moved abroad under the 1985 Plaza Accord (Ohno et al. 2009). In Southeast Asia, the approach to improving quality and productivity that underpins the operations of Japanese manufacturing industries has been introduced as part of long-term development. Japanese Foreign Direct Investment (FDI) and Official Development Assistance (ODA) contributed to this trend (JICA and JBIC 2008). Kaizen training has a positive effect on production management skills (Higuchi et al. 2015).

However, the methods by which Kaizen has been introduced, disseminated, and transformed in manufacturing industries in the context of specific Southeast Asian countries have not been thoroughly analyzed. Specifically, it is not yet known how the government and the private sector within each country have contributed to the dissemination process. It is

\footnotetext{
T. Homma ( $\bowtie)$

Senior Advisor, Japan International Cooperation Agency (JICA), Tokyo, Japan e-mail: Homma.Toru@jica.go.jp

(C) The Author(s) 2020

A. Hosono et al. (eds.), Workers, Managers, Productivity, https://doi.org/10.1007/978-981-15-0364-1_6
} 
essential to know how the government and the private sector can share the role of disseminating Kaizen in manufacturing industries so that government and donor community can consider how to intervene in Kaizen dissemination.

The patterns of Kaizen dissemination in Southeast Asian countries differ depending on their circumstances but can be categorized into government led and private sector led. Under the strong leadership of the government, the government-led pattern aims to improve productivity/ quality, such as by introducing Kaizen systematically and often with the establishment of an exclusive public organization on productivity improvement. Singapore ${ }^{1}$ and Malaysia are typical examples of this. In the private sector-led pattern, active investment by Japanese manufacturing companies and the establishment of factories in host countries, coupled with the formation of a supply chain involving local supporting industries, have brought about close business ties with local suppliers. Under such relationships, Japanese manufacturers, especially those in the automobile and electronics industries, actively introduce Kaizen to improve the quality and productivity of the local suppliers of parts and components. Thailand ${ }^{2}$ and Indonesia are examples of this, although the former also has a strong government initiative in place.

This chapter compares the experiences of Malaysia and Indonesia, considered to represent the variations in these two patterns. The chapter examines the patterns in the introduction, diffusion, customization, and evolution of Kaizen in each country, focusing on the roles of government and the private sector.

In addition to Malaysia and Indonesia, Myanmar, which just opened up its economy in 2011, is another case study. In Myanmar, there is neither a strong government initiative nor a significant private sector movement in the manufacturing supply chain. However, there have been sporadic attempts by individual companies and organizations to introduce Kaizen.

As Kaizen is an integral part of Japanese-style management, some Japanese organizations ${ }^{3}$ actively disseminate Kaizen in Southeast Asia for the mutual benefit of Southeast Asian countries and Japan.

\section{Research Methodology}

The research for this chapter is based on semi-structured interviews carried out in Malaysia, Indonesia, Myanmar, and Japan. In Malaysia, a series of semi-structured interviews were conducted in January 2018 
with 11 Malaysia Productivity Corporation (MPC) officials (9 former management officials since the 1960s and 2 current ones), and 8 Malaysianbased companies mainly in the manufacturing industry. Similar interviews were conducted in Indonesia in January 2018, in Myanmar in February 2018, and in Japan sporadically from December 2017 to March 2018.

In addition to these interviews, Japan International Cooperation Agency (JICA) conducted a field enterprise micro-data survey in Indonesia from August to November 2017 to provide for an empirical analysis of supply chains and production networks under an industrial study project. The field survey was conducted by a contracted research team in the Institute for Economics and Social Research, Faculty of Economics, University of Indonesia (LPEM-FEUI ${ }^{4}$ ). This JICA-LPEM survey itself was composed of two parts: (a) a national-level survey in major cities with 262 interviewees and (b) a metalworking small and medium enterprise (SME) cluster in the Tegal Regency of the Central Java Province with 500 interviewees. This survey was not necessarily designed for this chapter but partially covered Kaizen-related questions and is utilized for this chapter's study (JICA and NRI 2019).

Based on the research methodology presented in this section, the following three (3) sections describe the dissemination of Kaizen in Malaysia, Indonesia, and Myanmar. The three sections are followed by aggregated findings from the research and then conclusions and implications.

\section{Kaizen Dissemination in Malaysia}

\subsection{The Malaysia Productivity Corporation (MPC) as the Key Driver for Kaizen Dissemination}

Malaysia has 31.6 million people (estimated in 2017$)^{5}$ with a GDP of US\$ 296 billion (current US\$ in 2015). Its GDP per capita is close to US\$ 10,000 (current US\$ 9768 in 2015). Its industry sector contributes to its economy and accounts for 39.6 percent (estimated in 2017) of gross value added (GVA). The electric and electronics, automobile, and other manufacturing industries emerged during the rapid industrialization process that began in the 1970s. Malaysia also has a strong government initiative toward industrialization, in particular during Prime Minister Mahathir's first term since the 1980s to early 2000s. Malaysia conducts a unique national car program such as Proton and Perodua, which aggregately have been overwhelming foreign car manufacturers including Japanese, although national car shares have been declining recently (JICA and IDCJ 2017). 
Under the leadership of the Malaysian government, the Malaysia Productivity Corporation (MPC) has played a significant leading role in productivity/quality improvement since the setup of its predecessor the National Productivity Centre (NPC) in 1962 as a joint project between the United Nations (UN) and the International Labour Organization (ILO). The NPC became a statutory body in 1966, was transformed into the National Productivity Corporation (NPC) in 1991, and was finally renamed the Malaysia Productivity Corporation (MPC) in 2008. MPC itself has been evolving overtime. Its main focus has shifted from human resource development to productivity awareness, research and development, and competitiveness and innovation. MPC has approximately 200 staff members and it provides training programs, corporate consultation services, research and development, information, publications, system development, and other services (MPC 2018 and NPC 2006).

Kaizen and associated Japanese methodologies were introduced into Malaysia through the Malaysia Productivity Corporation (MPC), particularly through the Look East Policy, a Malaysian government initiative to learn from the nation-building experiences of Japan (and Korea) in 1983. Thousands of Malaysian people from the government, NPC, private sector, and academia were dispatched to Japan as trainees and students to learn from Japan including Kaizen. Once Kaizen was introduced into NPC/MPC, the Kaizen tools were customized to suit the Malaysian way of doing things and MPC's comprehensive approach. Typical examples are " $5 S$ " and the "Quality Control Circle (QCC)," which were customized as "Quality Environment (QE)" and the "Innovation and Competitiveness Circle (ICC)" (MPC 2013).

JICA and IDCJ (2018) suggest that the government-created NPC (now Malaysia Productivity Corporation (MPC)) was given a pioneering role in productivity and quality improvement and produced human resources for industries, together with the following training programs under the Look East Policy. The Association for Overseas Technical Cooperation and Sustainable Partnerships (AOTS) and the Asian Productivity Organization (APO) also provided training programs for industries. These formed the basis for Malaysian industry and multinational companies (MNCs), including Japanese automobile and electronic industries, to introduce their productivity improvement approaches including Kaizen. MNCs also contributed to the dissemination of Kaizen in Malaysia through their supply chain. Maarof and Mahmud (2015) suggested continuous improvement by Kaizen is necessary for Malaysian SMEs for improving their performance.

In Malaysia, Kaizen has been understood in various ways but has generally been integrated as a part of a comprehensive productivity improvement 
system, together with Total Quality Management (TQM), Lean Management, and Six Sigma, rather than the prevailing Kaizen umbrella concept. That being said, its core concept is well recognized as "continuous improvement" and it is considered as an effective tool to motivate gemba (the factory floor), according to the series of interviews.

\subsection{Results from Semi-structured Interviews}

This subsection discusses the value of Malaysia Productivity Corporation (MPC) as a contributor to Kaizen dissemination in the Malaysian manufacturing sector. The series of semi-structured interviews ${ }^{6}$ carried out in Malaysia reveals that MPC interviewees strongly agreed-at a 4.82 average on a scale ${ }^{7}$ of $0-5$ - that the MPC has contributed to productivity and quality improvement in the Malaysian manufacturing sector. Likewise, the MPC interviewees strongly agreed - at a 4.55 average on the same scalethat the MPC has been contributing to dissemination of Kaizen. Meanwhile they agreed at a slightly lower level of 3.27 point on the same scale that productivity/quality improvement approaches have been well disseminated in the Malaysian manufacturing sector because dissemination at SME level has not been fully achieved. Interviewed companies noted at a level of 4.75 that productivity/quality improvement approaches such as Kaizen are useful for their operations. These data are shown in Fig. 6.1.

This result represents a limited number of views and is biased because it is Malaysia Productivity Corporation (MPC's) self-evaluation and interviews on Kaizen by Japanese interviewers. However, it is significant that it shows relatively strong recognition by ex-MPC high-level officers and interviewed companies of the MPC's contribution to productivity and quality improvement in the manufacturing sector in Malaysia, as well as that of Kaizen. At the same time, the usefulness of productivity/quality improvement approaches such as Kaizen is also well recognized.

From a series of interviews, Malaysia Productivity Corporation (MPC's) strengths can be summarized as follows: (a) strong mandate to lead productivity improvement in Malaysia, (b) appropriate and timely adaptation/shift of MPC's function along with necessities, (c) customization of foreign practices such as Kaizen to the Malaysian culture, and (d) a wide variety of services to deliver such services efficiently.

In summary, Malaysia Productivity Corporation (MPC) has played a significant role in Kaizen dissemination in Malaysia's manufacturing sector reflecting strong government initiative in productivity improvement and it has triggered the private sector's own contributions to Kaizen dissemination in Malaysia. 


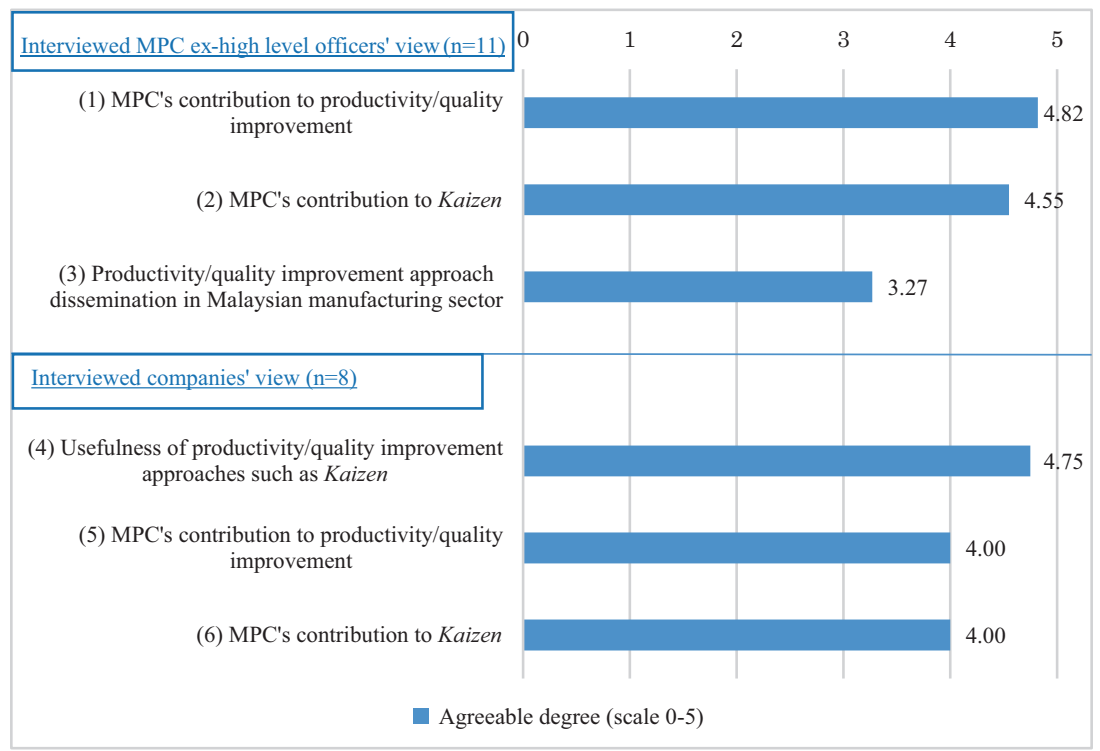

Fig. 6.1 Subjective recognition on dissemination of productivity/quality improvement approach such as Kaizen in the manufacturing industry in Malaysia. (Source: Author)

\section{Kaizen Dissemination in Indonesia}

\subsection{Kaizen Dissemination Through Supply Chain Transaction}

Indonesia has the largest population in Southeast Asia and the fourth larg-

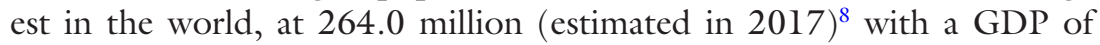
US $\$ 861$ billion (current US\$ in 2015). Hence its domestic market potential is huge. Indonesia's GDP per capita is US\$3347 (current US\$ in 2015), which is just above the commonly considered threshold (US\$3000 per capita) to begin rapid motorization. Its industry sector counts at 41.3 percent (estimated in 2017) of GVA. Indonesia is the second largest automobile producer and has the largest market in Southeast Asia at around 1.2 million per year. After the 1970s, almost all major Japanese automobile assemblers settled their factories under joint venture with local capital and they count much more than 90 percent of automobile domestic production share ${ }^{9}$ in Indonesia. They have established firm supply chain networks involving several hundreds of local suppliers from tier-1 (those 
that produce parts and components and supply them directly to the assemblers) and tier-2 (those that produce parts and components and supply them to tier-1 companies), and further subcontracting local smaller parts and component manufacturers.

In Indonesia, the private sector played a significant role in introducing Kaizen, in particular, the factory operations of Japanese manufacturers and their supply chain transactions with local suppliers. They act as the vehicles for disseminating Kaizen in Indonesia. For example, an automobile manufacturing company identifies several local suppliers every year and provides an intensive program for them to acquire practical quality and productivity improvement methodologies including Kaizen. Compared to Malaysia's, Indonesia's private sector played a more significant role in disseminating Kaizen in its manufacturing sector.

Figure 6.2 shows that the JICA-LPEM survey ${ }^{10}$ reveals that 77.5 percent of the surveyed companies $(n=262)$ conduct Kaizen $n^{11}$ and 84.4 percent of them do $5 \mathrm{~S} .{ }^{12}$ The surveyed companies obtain information/ services/support from around 40 percent of their customer companies, ${ }^{13}$ while they also receive information/services/support from 25 to 30 percent of their suppliers. ${ }^{14}$ With an average of 207.7 employees, the surveyed companies are relatively large-scale companies, ${ }^{15}$ capable ${ }^{16}$ enough to systematically learn and implement Kaizen.

While many surveyed companies rely on Kaizen-related information/ services/support from their customer companies and suppliers, fewer surveyed companies also obtain such information/services/support from other companies (domestic/foreign/SOE ${ }^{17}$ ) within their supply chain (customers/suppliers), government, or $\mathrm{NGO} / \mathrm{CSO}^{18}$ as shown in Fig. 6.2(b). This implies ${ }^{19}$ that some surveyed companies obtain Kaizenrelated information/services/support from multiple sources, including non-supply chain companies, governments, and others, but less frequently than from their supply chain companies (customers/suppliers).

\subsection{The Effectiveness of Kaizen in Indonesia}

The JICA-LPEM Survey provides some clues on the effectiveness of Kaizen at least among the surveyed companies $(n=262)$ in major cities ${ }^{20}$ in Indonesia, disseminated mainly through their supply chain relationship. The Kaizen Engagement Index (KEI), created in this chapter and calculated using Eq. (6.1) below, is designed to show whether Kaizen and $5 \mathrm{~S}$ are implemented in a surveyed company and whether information/ 
services/support for Kaizen/5S are provided by its customer companies. KEI's score is calculated on a $0-10$ scale.

Kaizen Engagement Index $(\mathrm{KEI})=\left(c k+c f+\sum_{i=1}^{5} k c_{i} / 5+\sum_{i=1}^{5} f c_{i} / 5\right) / 2.5$

where $c k$ is a yes/no variable showing whether a surveyed company conducts Kaizen for its production process improvement and $c f$ is a yes/no variable showing whether the surveyed company conducts $5 S$. The vari-

a

$$
\begin{array}{llllllllllll}
\% & 0 & 10 & 20 & 30 & 40 & 50 & 60 & 70 & 80 & 90 & 100
\end{array}
$$

(1) Conducting Kaizen by own

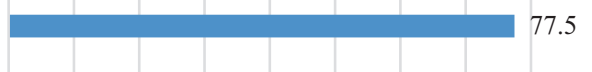

(2) Conducting $5 \mathrm{~S}$ by own

(3) Support from Customers: Kaizen

(4) Support from Customers: $5 \mathrm{~S}$

(5) Support from Suppliers: Kaizen

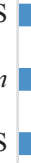

(6) Support from Suppliers: 5S

25.4

29.6

b

Support fromother than their suppliers/customers such as ...

$$
\begin{array}{llllllllllll}
\% & 0 & 10 & 20 & 30 & 40 & 50 & 60 & 70 & 80 & 90 & 100
\end{array}
$$

(7) Other domistic company Type 1

(8) Other domistic company Type 2

(9) Other domistic company Type 3

(10) Other foreign company Type 1

(11) Other foreign company Type 2

(12) Other foreign company Type 3

(13) Other foreign company Type 4

(14) Other SOE Type 1

(15) Other SOE Type 2

(16) Other SOE Type 3

(17) Central Government

(18) Local Government

(19) $\mathrm{NGO} / \mathrm{CSO}$ 
able $k c_{i}$ is the variable that shows whether the top-five customers provide information/services/support for Kaizen to the surveyed company, and $f c_{i}$ shows whether the top-five customers provide information/services/ supports for $5 \mathrm{~S}$. As the maximum value of the KEI should be 25 , it is divided by 2.5 to be on a $0-10$ scale.

In other words, the Kaizen Engagement Index (KEI) values how a company is engaged in Kaizen/5S activities from the following two (2) aspects, which is also presented in Fig. 6.2(a):

1. Kaizen/5S implementation: How far a company implements Kaizen/5S by themselves.

Fig. 6.2 Indonesian companies' involvement in Kaizen and $5 \mathrm{~S}$ implementation and information/services/supports from outside: (a) Kaizen/5S implementation by own and Kaizen/5S information/services/supports from their customers and suppliers $(n=262)$, (b) (for reference) Information/services/supports on Kaizen, $5 S$, QC (Quality Control), and others from other type of companies or institutions (other than their customers and suppliers). Note 1: "Support" in this figure means information/services/support gained from someone outside their companies, such as their customers (such as the companies that order the surveyed companies to make products/components), their suppliers (such as the companies that supply material/parts for the surveyed company's production), and others listed in the (b) above. Note 2: The sample size was 262 except for the following: 922 for (3) and (4) and 786 for (5) and (6), because the 262 respondents were asked to list their multiple major customers/suppliers at maximum five (5). Note 3: In the items from (7) to (16), Type 1 refers to a company within the same province with the surveyed company; Type 2 means a company in a different province but within the same island with the surveyed company; Type 3 means a company on a different island as the surveyed company but within Indonesia; Type 4 means a company outside Indonesia; SOE means State-owned enterprise; and NGO/CSO means nongovernmental organization/civil society organization. Note 4: $5 \mathrm{~S}$ is a working environment improvement methodology including Seiri (Sort/orderliness), Seiton (Set in order/tidiness), Seisou (Shine/cleaning up), Seiketsu (Standardize/cleanliness), and Shitsuke (Sustain/discipline) (Shimada et al. 2013). Note 5: This JICA-LPEM Survey inquires about Kaizen and 5S separately in some parts (such as the data used for Fig. 6.2(a)) and aggregately on Kaizen and 5S, and furthermore includes other types of management activities such as QC, ISO, and others in other part (such as the data used for Fig. 6.2(b)). This is because this survey was not necessarily designed for this chapter but for other purposes. However, the survey is still useful for discussions on Kaizen dissemination in Indonesia in this chapter. (Source: Processed by Author, data derived from JICALPEM Survey) 
Fig. 6.3 Relationship between Kaizen engagement and labor productivity $(n=262)$. Note: IDR means Indonesian rupiah (Indonesian currency). (Source: Processed by Author, data derived from JICA-LPEM Survey)

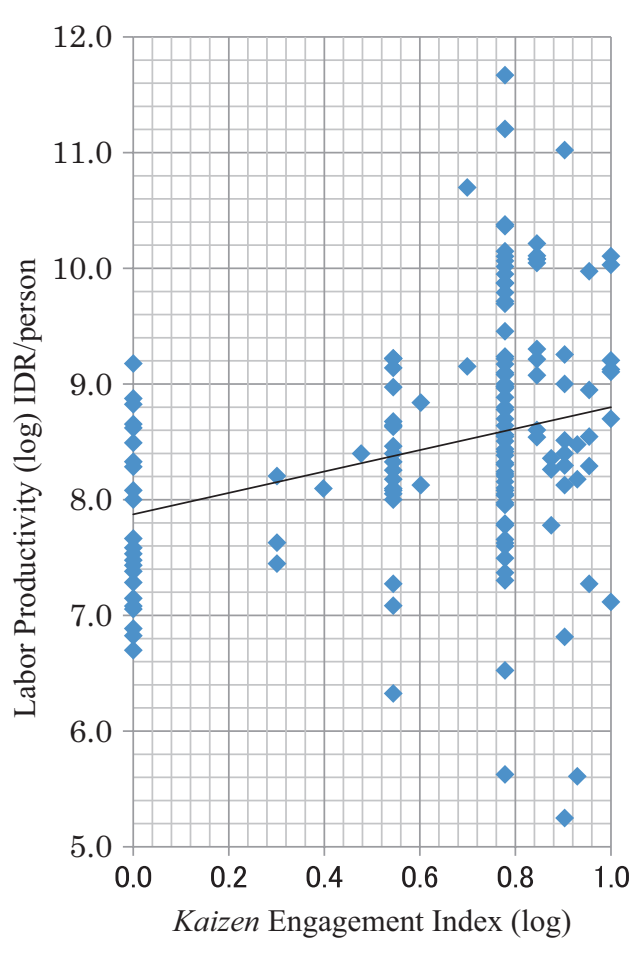

2. Access to information/service/support for Kaizen/5S via its customers.

Figure 6.3 shows a mild correlation between the Kaizen Engagement Index (KEI) and labor productivity for the surveyed companies $(n=179$, where labor productivity value is available) in Indonesia ( $t$ value $=3.912$, $p<0.05$, Pearson's correlation coefficient: $r=0.28211$ ). This implies the possibility that companies engaged in Kaizen/5S by themselves and/or support from their customers through their supply chain may achieve higher labor productivity, or in other words, Kaizen/5S by themselves and their customers' support may contribute to improved productivity.

The Indonesian field survey also reveals a mild correlation between Kaizen implementation and process innovation implementation $(t$ value $=3.564, p<0.05$, Pearson's correlation coefficient: $r=0.21585$, $n=262$ ). This implies that engagement in Kaizen in the supply chain may enhance process innovation. ${ }^{21}$ 


\subsection{The Role of Private and Public Organizations}

Apart from the survey results in the previous Subsects. 4.1 and 4.2, there are some more missing Kaizen players. ${ }^{22}$ Among them are various private sector organizations that have contributed to this process in Indonesia. There are two (2) major types. One works as a facilitator, including private associations dealing with QC Circle conventions on a large scale, such as the Indonesian Quality Management Association (IQMA) and the Indonesian Quality and Productivity Management Association (IQPMA). Both IQMA and IQPMA actively and separately organize annual QC Circle conventions involving several hundreds to thousands of participants mainly from private manufacturing companies, including domestic and foreign companies. The associations provide these companies with opportunities to improve their productivity and quality through Kaizen, 5S, and other quality control or productivity improvement approaches. At the same time, their annual conventions contribute to strengthening networks and disseminating Kaizen in Indonesian manufacturing industries. IQMA and IQPMA are also gateways to the international quality and productivity community; IQMA is a member of the International Convention on Quality Control Circles (ICQCC) and participates in annual conventions ${ }^{23}$ held in 13 member countries with some private companies. IQMA also hosted two ICQCC annual conventions in the past. IQPMA is a member of Asia Pacific Quality Organization (APQO).

Practical training institutes are another type of private sector organization. An automobile industry conglomerate's foundation that provides several training programs for SMEs, including Kaizen, is a typical case. This foundation utilizes Indonesian engineers in the group of automobile companies as trainers, and frequently delivers various training programs including Kaizen/5S among group companies as well as for SMEs outside the group as a part of the industry conglomerate's corporate social responsibility (CSR) activities.

In summary, the private sector has actively disseminated Kaizen mainly through two channels: (a) Japanese manufacturers and their local supply chains involving local suppliers through their supply chain management systems (Subsects. 4.1 and 4.2 in this chapter) and (b) private sector organizations to organize productivity/quality-related programs including conventions and training (Subsect. 4.3 in this chapter).

Meanwhile, the Directorate General of Training and Productivity Development under the Ministry of Manpower and Transmigration acts as 
Indonesia's National Productivity Organization against APO. Indonesia became a member of the APO in 1968 and the Ministry's approach for productivity improvement started at that time. The Ministry classifies past experiences with productivity improvement since then into three phases: (a) the awareness phase, (b) the improvement phase, and (c) the maintenance phase. It has accumulated experience and provides a kind of standard approach for productivity improvement in Indonesia.

\subsection{Conclusion on Kaizen Dissemination in Indonesia}

As discussed throughout Sect. 4, the private sector supply chain flow (customer companies and supplier relationships) in Indonesia effectively disseminates Kaizen through the provision of information/services/ support, rather than other sources (Subsect. 4.1). Analysis of the Kaizen Engagement Index (KEI) implies that a company's engagement in Kaizen either on its own or with information/services/support from its customers through its supply improves labor productivity (Subsect. 4.2). The organization of productivity/quality-related programs, including conventions and training, is another means by which the private sector disseminates Kaizen in Indonesia (Subsect. 4.3). On the whole, the private sector seems to have a more central role to disseminate Kaizen in Indonesia.

\section{Kaizen Dissemination in Myanmar}

\subsection{Kaizen-Disseminating Organizations}

Myanmar is considered the last promising investment destination in Southeast Asia, thanks to its rapid open-up reform since 2011 under the transition period toward democratization. Its untapped domestic market of 53.4 million people (estimated in 2017) ${ }^{24}$ attracts investors to this emerging market. Its GDP is US\$ 62.6 billion (current US\$ in 2015) and its GDP per capita is rapidly growing from US\$ 239 in 2005 to US\$ 1162 in 2015 (current US\$). The industry sector's share in Myanmar's economy amounts to only 14.6 percent (estimated in 2017) of GVA. Its economy including the manufacturing sector is growing rapidly, but the sector is concentrated in the labor-intensive garment sector and it is still in its infancy, without a firm industrial structure with established supply chain, such as the manufacturing of automobiles and their parts and components. Some companies have introduced Kaizen by chance on their own 
with limited external support. There may be room to learn from the Malaysian and Indonesian experiences.

The Myanmar Productivity Center (MPC) was created in 2016 as a small unit within the Union of Myanmar Federation of Chambers of Commerce and Industry (UMFCCI) with the support of the Japan Productivity Center (JPC). In the two years of activities since then, three MPC Kaizen consultants were certified and another three were nominated as candidate MPC Kaizen consultants. MPC identified nine Myanmar manufacturing companies as model companies in the last two years and JPC provided each of them with three consultations at their factories. The establishment of the MPC was endorsed in the Industrial Policy issued in 2016 by the Ministry of Industry of Myanmar.

As another Japanese collaboration with the UMFCCI, the MyanmarJapan Center for Human Resource Development (MJC) is supported by the Japan International Cooperation Agency (JICA) as its technical cooperation project with the Ministry of Commerce of Myanmar. Approximately 400 training courses and seminars have been provided for close to 15,000 participants in total, mainly from Myanmar SMEs, in the five years since its establishment in 2013. Around 20 percent of these were in relation to Japanese-style management and continuous improvement (Kaizen), according to the MJC. JICA also assisted the Ministry of Industry to conduct 5S seminars in Myanmar in 2018 through a technical cooperation project.

The Association for Overseas Technical Cooperation and Sustainable Partnerships (AOTS) of Japan also provides training for industrial human resource development. Since 1959, some of around 2000 trainees have been dispatched from Myanmar to Japan for training programs, while around 6000 trainees have been trained in Myanmar in the same period. A major part of these training programs in Japan and Myanmar are management training programs that focus on Kaizen and 5S. Other training courses have many flavors of the basics of Japanese-style management approaches.

\subsection{A Case Study in the Private Sector}

One of the leading electric and electronic manufacturing companies in Myanmar (Company A, located in Yangon, with approximately 300 employees) provides good practice in Myanmar. Its long journey on productivity improvement started in 1997 when the current owner partici- 
pated in a Malaysian Training Cooperation Program organized by the Malaysia Productivity Corporation (MPC) in Malaysia. Immediately after he came back from this training, he introduced a series of Kaizen approaches, starting with $5 \mathrm{~S}$ in his factory. He produced a $5 \mathrm{~S}$ pocket handbook in the Myanmar language and set up 5S Day. Second, he introduced QC Circle in his factory. He also participated in a training course organized by AOTS and held in Yokohama in 2003. He continuously followed what he learnt from the training and through his own process. He then introduced Total Productive Maintenance (TPM) and finally reached ISO 9001, and Company A was certified in 2004 within only eight months. He has not just introduced Kaizen as he learned, but always considered the importance of "adopt, adapt, and adjust" according to the actual situation. For example, he skipped Total Quality Management (TQM) as he thought it was too early to introduce it into his factory.

His effort has been gradually disseminated outside his factory as an interesting approach. Company A was awarded by the Yangon City Mayor for his effort and invited to introduce the $5 \mathrm{~S}$ concept to the Yangon township administration. He then became a Joint Secretary General of the UMFCCI, in charge of the establishment of the Myanmar Productivity Center (MPC). He is now one of the most influential business people. Still he continuously learns Kaizen and implements "continuous improvement" day by day, which is the most essential meaning of "Kaizen." In 2016, his company was accepted as a model company of the MPC training course and received consultations from Japanese experts dispatched by JPC.

Thus far Kaizen dissemination in Myanmar is still limited, but voluntary sporadic initiatives have been popping up, especially in the private sector. It is expected that such initiatives will be streamlined along with rapid economic growth and industrial development.

\section{Major Findings and the KaIZEN Dissemination Model}

This research has examined how Kaizen has been disseminated in Southeast Asia, focusing on three countries as typical cases: Malaysia, Indonesia, and Myanmar. The process is complicated, although the major findings can be summarized as follows. 


\subsection{Stakeholders' Roles and Relations in Kaizen Dissemination (Possible Standard Model)}

First, there are various stakeholders, organizations, and institutions disseminating Kaizen in Southeast Asia, both in the government (such as ministries in charge and public productivity organizations like Malaysia Productivity Corporation (MPC) in Malaysia) and in the private sector (local suppliers and assemblers). There are also some active private or semi-private organizations such as quality control organizations and training institutes that provide services on a fee basis. Some of them are relatively common across the countries, while there are some country-specific private entities engaged in Kaizen dissemination, for example, Indonesia's IQMA and IPQMA. Contributions from various Japanese and Japanbased organizations to each stakeholder can be seen in the three countries, developing managerial and technical capability, training programs, expert dispatch programs, model consultation programs, policy/planning support, and financial assistance. They mainly support Kaizen dissemination through their counterpart organizations in the recipient countries. In general, standard stakeholders for Kaizen dissemination in Southeast Asia (at least in the three countries studied in this chapter) can be summarized as indicated in Fig. 6.4. The figure illustrates the supply chain network (in the shaded and rounded rectangular shape) that mobilizes Kaizen dissemination toward local manufacturers as local suppliers, while there are various public and private organizations that provide Kaizen services directly to local manufacturers and thereby contribute to Kaizen dissemination in the local industries.

\subsection{Government- or Private Sector-Led Kaizen Dissemination}

Second, however, as set out in the hypothesis at the beginning of this chapter, the Malaysian government (or more precisely Malaysia Productivity Corporation (MPC) as the public organization in Fig. 6.4) took the initiative disseminating Kaizen in Malaysia. On the other hand, Kaizen dissemination in Indonesia has been led by the private sector, particularly through supply chain mechanism and contributions by private organizations, as shown in a series of interviews and some results from the field survey.

What is the cause for this difference between the two countries? Are there any factors determining whether the process is led by the government or the private sector? 


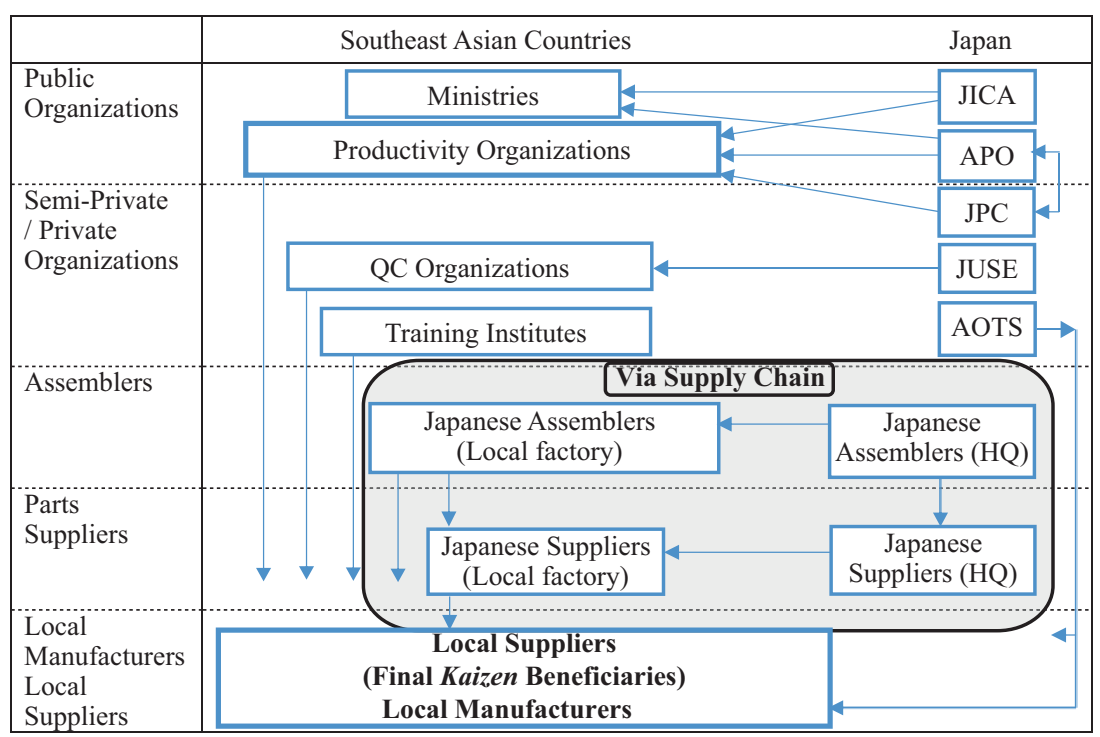

Fig. 6.4 Stakeholders' roles and relations in Kaizen dissemination (possible standard model). (Source: Author)

The first factor is how firmly established the supply chain within the country led by Japanese assemblers is. As mentioned in Sect. 4, Indonesia is the second largest automobile producer in Southeast Asia and after the 1970s, almost all major Japanese automobile assemblers settled their factories under joint venture with local capitals contributing more than 99 percent of its domestic production share. It is this deep, long-lasting supply chain structure in Indonesia that nurtures Kaizen dissemination through the private sector supply chain path. Meanwhile, although Japanese car manufacturers also contributed a lot to Kaizen dissemination in Malaysia, their presence there is not as strong as that in Indonesia partially due to the national car program. Myanmar's car manufacturing industry is still too premature to build up automobile production supply chain.

The second factor is the government's strength and willingness to disseminate productivity improvement such as Kaizen. Malaysia has already established an exclusive and professional governmental body Malaysia Productivity Corporation (MPC) to disseminate productivity improvement more than half century ago and has been acting as a leading organization. 
Finally, comparing the first and second factors determines the tendency for either the government or the private sector to lead. The private sector is stronger in Indonesia, while in Malaysia the government is. Thus, Kaizen dissemination in Malaysia is considered to be government-led while in Indonesia it is private sector-led. It is still too early to determine whether Myanmar is government or private sector led, although the private sector-some of which are supported by Japanese organizationsseems to be slightly more active.

\subsection{Kaizen Dissemination Path Model: Five-Stage Paths of Kaizen Dissemination}

Third, there are stages or phases of Kaizen dissemination. As we can see from the cases of each country presented in this chapter and others, Kaizen cannot be disseminated overnight. At the beginning, an introduction is necessary for those unfamiliar with Kaizen. Then it will be diffused through certain channels with practical activities. During this introduction and diffusion, some may notice the need to customize the approach to Kaizen according to their ecosystem. These movements finally produce the need for standardization within a country, as illustrated in Fig. 6.5(a): the "Kaizen Dissemination Path Model."

The five stages in the Kaizen Dissemination Path Model above can be described as follows:

1. Introduction: Kaizen is introduced as basic knowledge through translation, publication, seminars, lectures, training, pilot implementation, and other methods based on the experiences of Japan and other experienced countries. The core purposes of this stage are raising awareness and introducing potential benefits.

2. Diffusion: After the introduction stage, those who experience Kaizen and find it useful involve others in Kaizen practice and multiply Kaizen practitioners. At this stage, measures and activities related to Kaizen become more practical and systematic, for example, the training of trainers (TOT), technical consultations within companies, in-company training, and others.

3. Customization: Based on the experience at the introduction and the diffusion stages, related people and organizations accumulate knowledge and experience and identify areas to be modified according to their own custom and culture. Examples include the Malaysian 
a

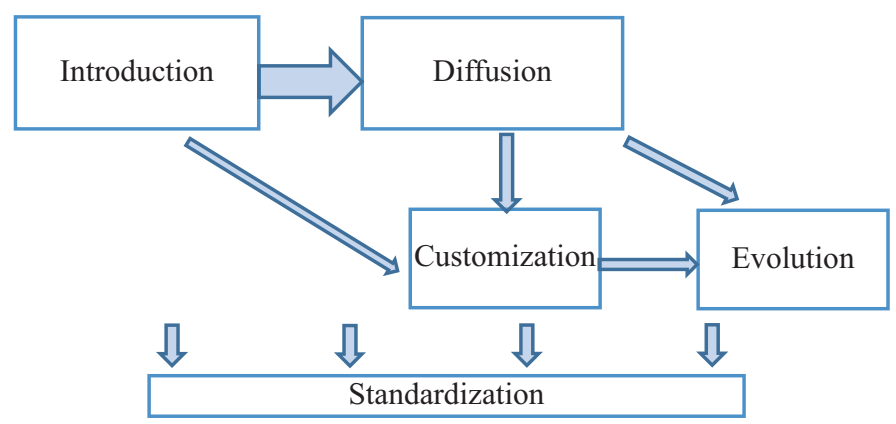

b

\begin{tabular}{|l|l|l|l|}
\hline \multirow{2}{*}{} & \multirow{2}{*}{$\begin{array}{l}\text { Government / Public } \\
\text { organization }\end{array}$} & \multicolumn{2}{|c|}{ Private sector } \\
\cline { 2 - 4 } & Private organization & Private company \\
\hline Dissemination Stage & $\begin{array}{l}\text { Yes (For willing } \\
\text { companies) }\end{array}$ & $\begin{array}{l}\text { Yes (For own supply } \\
\text { chain) }\end{array}$ \\
\hline Introduction & $\begin{array}{l}\text { Yes (For General / } \\
\text { SMEs) }\end{array}$ & Yes (Public awareness) & $\begin{array}{l}\text { Yes (Within own } \\
\text { supply chain) }\end{array}$ \\
\hline Diffusion & $\begin{array}{l}\text { Yes (Public } \\
\text { awareness) }\end{array}$ & Yes (Country context) & $\begin{array}{l}\text { Yes (Group/company } \\
\text { context) }\end{array}$ \\
\hline Customization & Yes (Country context) & $\begin{array}{l}\text { Yes (Developing own } \\
\text { methodology) }\end{array}$ \\
\hline Evolution & $\begin{array}{l}\text { Yes (Developing } \\
\text { country methodology) }\end{array}$ & $\begin{array}{l}\text { Yes (Developing own } \\
\text { methodology) }\end{array}$ & Can contribute \\
\hline Standardization & $\begin{array}{l}\text { Yes (Most fit to } \\
\text { government role) }\end{array}$ & Partially Yes & Relatively Strong \\
\hline Country Context & Strong & Fair & Very strong \\
\hline Malaysia & Fair & Strong & Weak (partially Fair) \\
\hline Indonesia & Still weak & Fair & \\
\hline Myanmar & &
\end{tabular}

Fig. 6.5 Kaizen dissemination path model: Paths of Kaizen dissemination in a country: (a) dissemination stage outline and (b) dissemination stages and stakeholders' major roles (Source: Author) 
Malaysia Productivity Corporation (MPC's) transformation of $5 \mathrm{~S}$ into Quality Environment and the case of the company in Myanmar.

4. Evolution: In some cases, customization may advance beyond modification, for example, MPC's Innovation and Competitiveness Circle (ICC). ICC has evolved from the original version of Quality Control Circle (QCC) with more emphasis on innovation. Some forms of evolution may be considered "reverse innovation," meaning an innovation born in developing countries that moves to developed countries as a new approach.

5. Standardization: All the effort conducted in any of the four stages above may need to be summarized and documented as the standard procedure, methodology, or approach for the purpose of replicating such efforts by others. This contributes to Kaizen becoming firmly rooted in a country.

\subsection{Stakeholders' Major Roles in Kaizen Dissemination}

Fourth, each government/public organization, private organization, and private company have their roles and all of them may contribute to the dissemination of Kaizen. Although these roles may differ somewhat by country, Fig. 6.5(b) summarizes each party's possible major roles along with the dissemination stage designated in Fig. 6.5(a). It shows that each party (government/public organization, private organization, and private company) can contribute to each stage. However, their targets and directions often differ as indicated in brackets in each cell in Fig. 6.5(b). In this sense, close collaborations to complement each other in terms of mandates, capacity, financial resource, geographical coverage, access/reach, and so on may work. The bottom of Fig. 6.5(b) illustrates the relative strength of each party in each country.

\subsection{Proactive Role of Government and Public Organizations}

Fifth, government and public organizations can work proactively to disseminate Kaizen. Malaysia shows strong government/Malaysia Productivity Corporation (MPC) leadership and has already discussed proactive roles for Kaizen dissemination. Indonesia's case shows strong contributions from the private companies' supply chain management and various private organizations, but the government also raises awareness, 
standardizes the Kaizen methodology/philosophy, and acts as the country window for APO. In Myanmar government dissemination of Kaizen seems so far to be weak, but there may be room to support the private organization's initiative and private sector's sporadic movements.

\section{Conclusions}

This chapter has discussed the roles of stakeholders, particularly the government (including public organizations) and the private sector (private organizations and private companies) in three countries: Malaysia, Indonesia, and Myanmar. Each country shows a different path toward the dissemination of Kaizen, with a clear contrast between the governmentled Malaysian case and the private sector-led Indonesian case. However, all the stakeholders have their own roles in each of the three country cases and complement each other.

On the other hand, the dissemination of Kaizen can be summarized in the five-stage Kaizen Dissemination Path Model comprising Introduction, Diffusion, Customization, Evolution, and Standardization.

Finally, this research needs further comparative analysis among more Southeast Asian countries than just the three piloted countries to provide further numerical evidence to contribute to the emerging countries in Southeast Asia and other regions for them to disseminate Kaizen accordingly in each country.

\section{Notes}

1. Singapore has initiated a productivity movement under the strong leadership of then Prime Minister late Lee Kuan Yew. He requested that Japan conduct technical cooperation and Japan International Cooperation Agency (JICA) started the Productivity Development Project (PDP) in 1983 with Singapore's National Productivity Board (NPB) as the counterpart agency. It was the very first technical cooperation by JICA on productivity improvement or Kaizen in the world. Since then technical cooperation on Kaizen has been implemented all over the world, spread from Asia, Eastern Europe, Latin America, and Africa (Jin 2018).

2. The Thai government requested the Japanese government to provide technical cooperation to promote a national-level productivity movement and the Thailand Productivity Development Project from 1994 to 2001. Its implementing agency was Thailand Management Development and Productivity Center (TMDPC) established by the Thai government in 
1962 at the beginning of the Project and then followed by the new Thailand Productivity Institute (FTPI). From the private sector, Kaizen was already introduced into Thai companies especially from Japan in the 1990s (Jin 2018).

3. In the area of productivity improvement, the Japan Productivity Center (JPC) has been actively engaged in Kaizen by receiving trainees from Southeast Asia and dispatching experts. JPC is the national productivity organization for the Asian Productivity Organization (APO), whose lead donor is Japan and whose headquarters is located in Tokyo (JPC 1985). APO has been funding various programs on productivity through JPC and others. The Union of Japanese Scientists and Engineers (JUSE) has contributed to quality improvement through the International Convention on Quality Control Circles (ICQCC) and others. The Association for Overseas Technical Cooperation and Sustainable Partnerships (AOTS) has also received a great number of trainees in this area. Under its ODA program, the Japan International Cooperation Agency (JICA) has implemented a pioneering technical cooperation project on productivity in Singapore and Thailand (Hosono 2016), as well as other forms of cooperation such as training programs on Kaizen in Japan for other Southeast Asian countries. There have also been a number of JICA's technical cooperation projects on metal processing technology such as casting and mold/die in Indonesia, Malaysia, Thailand, and Philippines. These technical cooperation projects contained production control and quality control components, which naturally featured Kaizen (Homma 2009 and JICA 2004).

4. Lembaga Penyelidikan Ekonomi dan Masyarakat, Fakultas Ekonomi Universitas Indonesia.

5. The statistical data in this paragraph come from United Nations (2018) unless otherwise noted.

6. See the previous section on research methodology for further details of the interview.

7. The scale represents the level of agreement to each question. Scale 5 corresponds to "Strongly yes," Scale 4 "Yes," Scale 3 "Partially yes," Scale 2 "Neither yes nor no," Scale 1 "No," and Scale 0 "Strongly no."

8. The statistical data in this paragraph are from United Nations (2018) unless otherwise noted.

9. According to the Association of Indonesia Automotive Industries (GAIKINDO), Japanese brand car production share reaches 99.59 percent in 2016 out of Indonesia's annual production amount 1,177,797 vehicles.

10. See the previous Research Methodology section for further details.

11. In the field survey questionnaire, Kaizen is defined as any systematic activity in which workers discuss problems in the workshop and try to solve them and does not need to be called "Kaizen." 
12. In the field survey questionnaire, $5 S$ is defined as any systematic activity to clean the workshop and put products and materials together in an orderly way.

13. For example, in the case of tier-l car part and component manufacturer/ supplier, car assemblers that purchase tier- 1 companies' products (parts and components) are tier- 1 companies' customers.

14. For example, in the case of tier-1 car part and component manufacturer/ supplier, tier-2 companies that supply subparts and subcomponents for the tier-1 companies' production.

15. According to the definition of the Indonesia's national statistical agency Badan Pusat Statistik (BPS), a company with 100 or more employees is defined as a large company.

16. Their average year of operation is shown as 25.1 , meaning that these companies on average survived the Asian Monetary Crisis, which hit Indonesia around 1998.

17. State-owned enterprise.

18. Nongovernmental organization/civil society organization.

19. Although the questionnaire in Fig. 6.2(a) on customers/suppliers (supply chain) and Fig. 6.2(b) on non-supply chain sources is slightly different (see Notes of Fig. 6.2 for further details), the tendency for supply chain companies to be the preferred source can be seen.

20. Jakarta (Special Capital Region) and major cities in the provinces of Banten, West Java, Central Java, East Java, and Riau Islands.

21. It may be interesting to study how far conducting Kaizen can contribute to process innovation, for example, by increasing firm capability, in particular, managerial capability, which is the initial step to future innovation (Cirera and Maloney 2017).

22. This is due to the survey design and limitations. As previously mentioned, the survey is not necessarily exclusively designed for this chapter.

23. The ICQCC annual convention started in 1976. Since then, 42 annual conventions have already been held in 13 member countries in turn.

24. The statistical data in this paragraph are from United Nations (2018), unless otherwise noted.

\section{REFERENCES}

Cirera, Xavier, and William F. Maloney. 2017. The Innovation Paradox: DevelopingCountry Capabilities and the Unrealized Promise of Technological Catch-Up. Washington, DC: The World Bank Group.

Higuchi, Y., V.H. Nam, and T. Sonobe. 2015. Sustained Impacts of Kaizen Training. Journal of Economic Behavior and Organization 120: 189-206. 
Homma, Toru. 2009. Quality and Productivity Improvement: Experience of JICA's Project in Indonesia. Presentation prepared for the First Ethiopia-Japan High Level Forum on Industrial Development in Ethiopia, Addis Ababa.

Hosono, Akio. 2016. Industrial Strategies: Toward a Learning Society for Quality Growth. In Efficiency, Finance, and Varieties of Industrial Policy, ed. A. Noman and J.E. Stiglitz, 306-352. New York: Columbia University Press.

Imai, Masaaki. 1986. Kaizen: The Key to Japan's Success. New York: McGraw-Hill. Japan International Cooperation Agency (JICA). 2004. Final Report on the Project on Supporting Industries Development for Casting Technology. Tokyo: JICA.

Japan International Cooperation Agency (JICA) and International Development Center of Japan (IDCJ). 2017. The Study on Achievements and Roles by Japanese Official Development Assistance for Social and Economic Development in Malaysia: Final Report. Tokyo: JICA.

- 2018. The Study on Applying Development Experience A on Third Country Training Programme in Malaysia: Final Report. Tokyo: JICA.

Japan International Cooperation Agency (JICA) and Japan Bank for International Cooperation (JBIC). 2008. Report of the Stocktaking Work on the Economic Development in Africa and the Asian Growth Experience. Tokyo: JICA.

Japan International Cooperation Agency (JICA) and Nomura Research Institute (NRI). 2019. Data Collection Survey on Promotion for Globally Competitive Industry: Final Report. Tokyo: JICA.

Jin, Kimiaki. 2018. Role of Kaizen in Japan's Overseas Development Cooperation. In Applying the Kaizen in Africa: A New Avenue for Industrial Development, ed. K. Otsuka, K. Jin, and T. Sonobe, 31-68. Cham: Palgrave Macmillan.

Maarof, Mohd Ghazali, and Fatimah Mahmud. 2015. A Review of Contributing Factors and Challenges in Implementing Kaizen in Small and Medium Enterprises. New York: Elsevier B. V.

Malaysia Productivity Corporation (MPC). 2013. Quality Environment: Step-bystep Implementation. Petaling Jaya, Malaysia: MPC.

- 2018. Malaysia Productivity Corporation (MPC). Petaling Jaya, Malaysia: MPC.

National Productivity Corporation (NPC). 2006. 40 years NPC 1966-2006Productivity \& Quality for Competitiveness. Petaling Jaya, Malaysia: NPC.

Nihon Seisannsei Hombu (in Japanese, Japan Productivity Center: JPC). 1985. Seisansei Undo 30 Nenshi [Productivity Movement over 30 Years]. Tokyo: JPC.

Ohno, I., K. Ohno, and S. Uesu. 2009. Introduction. In Introducing Kaizen in Africa, ed. the GRIPS Development Forum, 1-12. Tokyo: GRIPS.

Shimada, G., T. Homma, and H. Murakami. 2013. Industrial Development of Africa. In For Inclusive and Dynamic Development in Sub-Saharan Africa, ed. JICA, 173-194. Tokyo: JICA Research Institute.

United Nations. 2018. UN Data. Accessed June 2018. http://data.un.org. 
Open Access This chapter is licensed under the terms of the Creative Commons Attribution 4.0 International License (http://creativecommons.org/licenses/ by $/ 4.0 /)$, which permits use, sharing, adaptation, distribution and reproduction in any medium or format, as long as you give appropriate credit to the original author(s) and the source, provide a link to the Creative Commons licence and indicate if changes were made.

The images or other third party material in this chapter are included in the chapter's Creative Commons licence, unless indicated otherwise in a credit line to the material. If material is not included in the chapter's Creative Commons licence and your intended use is not permitted by statutory regulation or exceeds the permitted use, you will need to obtain permission directly from the copyright holder.

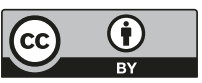

